\title{
Effect of ultrasound on drying kinetics of El Henna leaves (Lawsonia inermis)
}

\author{
Bennaceur, S. ${ }^{\text {a*}}$; Bennamoun, L..$^{\text {b }}$ Mulet, A. ${ }^{\text {c }}$ Draoui, B. ${ }^{\text {a }}$; Carcel, J. A. ${ }^{\text {c }}$ \\ ${ }^{a}$ Laboratoire d'Energétique en Zones Arides, Université Tahri Mohamed de Béchar, Algeria. \\ ${ }^{\mathrm{b}}$ Department of Mechanical Engineering, University of New Brunswick, NB,Canada. \\ c ASPA group, Department of Food Technology, Universitat Politècnica de València, Valencia, \\ Spain.
}

*E-mail of the corresponding author: bssaide@yahoo,fr

\begin{abstract}
In this work the influence of some process variable on drying rate of henna leaves was studied. For this reason, henna leaves were dried $(1 \mathrm{~m} / \mathrm{s})$ with and without ultrasound application at three temperatures, 40, 50 and $60^{\circ} \mathrm{C}$. As can be expected, the higher the temperature the faster the drying process. Ultrasound application increase drying rate at every temperature tested. Drying kinetics were modeled by using different experimental models. Weibull model provided the best fit for henna leaves drying kinetics.
\end{abstract}

Keywords:Ultrasonic; Weibull model; henna leave; temperature. 


\section{Introduction}

Henna (Lawsonia inermis) leaves (Fig. 1) is an important product consumed widely in Algerian society. This plant is found mainly in the southern region of Algeria and it is available eight months a year. Its height can reach $2-3 \mathrm{~m}$ at the end of its life. The dark green oval leaves (2-4 cm long) present hih interest not only for cosmetic but also for medicinal issues [1].

Among the methods used to conserve medicinal plants, drying is one of the most extended. The reduction of the moisture content prevents the degradation of this material [2] making possible its use for different applications [1]. The traditional drying of henna by exposition to the sun is being substituting by convective hot air drying. This permits to standardize the production and avoid problems such as contamination with particles (dust) or insects. However, drying can highly affect the quality attributes of henna leaves. Therefore drying kinetics studies can contribute to the better understanding of the process and select the best drying conditions that permits to obtain a high quality product.

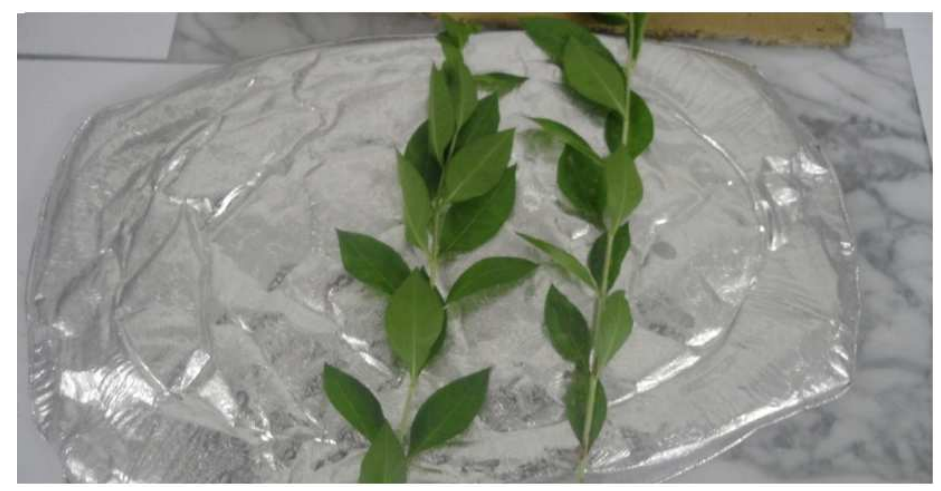

Fig. 1 The fresh leaves of El henna (Lawsonia inermis).

High intensity ultrasound has been used to intensify drying process. This could permit the use of milder drying conditions that can improve the product quality. Thus, the aim of this work was to determine the drying kinetics of henna leaves at different temperatures and quantify the influence of the application of ultrasound during the process. 


\section{Materials and Methods}

\subsection{Experimental drying}

\subsubsection{Sample preparation}

The henna leaves studied were cultivated and neatly transported by air from the wilaya of Béchar, in the south west of Algeria, to the laboratory of the Analysis and Simulation of Agro-food Process (ASPA) research group, Food Technology Department, Universitat Politècnica de València, Spain. There, they were stored in a refigerator at $5 \pm 1{ }^{\circ} \mathrm{C}$ until drying experiments. The moisture content was measured by placing the samples in a vacuum oven at $70{ }^{\circ} \mathrm{C}$ and $200 \mathrm{mmHg}$ until constant weight, following standard method $\mathrm{n}^{\circ} 934.06[3]$.

\subsubsection{Experimental drying kinetics}

Drying kinetics were carried out in an ultrasonically-assisted convective dryer previously described [4,5]. This equipment is a laboratory scale dryer modified to apply power ultrasound, with automatic control of the air temperature and velocity and provided with an automatic sample weighing system.

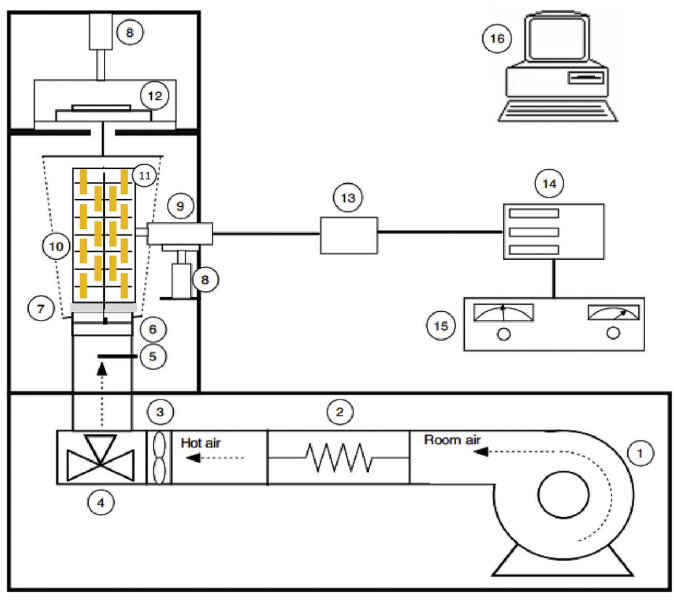

$\begin{array}{ll}01 & \text { Fan } \\ 02 & \text { Heating unit } \\ 03 & \text { Anemometer } \\ 04 & \text { Three-way valve } \\ 05 & \text { Thermo-couple } \\ 06 & \text { Sample loading chamber } \\ 07 & \text { Coupling material } \\ 08 & \text { Pneumatic moving arms } \\ 09 & \text { Ultrasonic transducer } \\ 10 & \text { Vibrating cylinder } \\ 11 & \text { Sample holder } \\ 12 & \text { Balance } \\ 13 & \text { Impedance matching unit } \\ 14 & \text { Wattmeter } \\ 15 & \text { High-power ultrasonic generator } \\ 16 & \text { PC }\end{array}$

Fig. 2 Scheme of ultrasonicallyassisted convective drier[6].

The drying experiments were carried out in triplicate at three different air temperatures (40, 50 and $60{ }^{\circ} \mathrm{C}$ ) without (Air) and with ultrasound application (Air+US; $21.7 \mathrm{kHz}, 20.5$ $\mathrm{kW} / \mathrm{m}^{3}$ ). In every case, an air velocity of $1 \mathrm{~m} / \mathrm{s}$ was used. The dehydration process was stopped when samples lost $75 \%$ of their initial weight. 


\subsection{Drying kinetics}

The evolution of moisture content of samples during drying was determined by weighting the henna leaves after different drying times and the initial moisture content [7]. The equilibrium moisture content of the henna leaves was experimentally obtained by placing the henna samples at the drying conditions for a very long time. This time was enough to have no difference in sample weight for two hour. Then the moisture content of samples was expressed in non-dimensional way by using Eq. 1 [8].

$$
M R=\frac{X(t)-X_{e q}}{X_{0}-X_{e q}}
$$

Where MR is the non-dimesional moisture content or moisture ratio, $\mathrm{X}(\mathrm{t})$ is the moisture content after a drying time ( $\mathrm{kg}$ water $/ \mathrm{kg}$ dry matter, d.m.), $\mathrm{X}_{0}$ is the initial moisture content of samples ( $\mathrm{kg}$ water $/ \mathrm{kg}$ d.m.) and $\mathrm{X}_{\mathrm{eq}}$ ( $\mathrm{kg}$ water $/ \mathrm{kg}$ d.m.) is the equilibrium moisture content.

\subsection{Mathematical modeling}

Given the complexity of the phenomena involved in the drying of a product, it has been proposed mathematical models of different complexity including theoretical and empirical models. Thus, theroretical models can provide parameters, such as diffusivity, than can help to better understand the drying process. On the other hand, empirical or semi-empirical relationships permit to describe the drying curves and quantify the influence of drying conditions on drying rate. [8] Thus, in the case of this work eight different empirical models were used to describe the drying kinetics (Table 1).

Table 1. Mathematical models applied to the experimental drying kinetics

\begin{tabular}{cc}
\hline Name of model & Model \\
\hline Newton & $M R=\exp (-k t)$ \\
Page & $M R=\exp \left(-k t^{n}\right)$ \\
Henderson and Pabis & $M R=a \times \exp (-k t)$ \\
Logarithmique & $M R=a \times \exp (-k t)+c$ \\
Tow term & $M R=a \times \exp \left(-k_{0} t\right)+b \times \exp \left(-k_{1} t\right)$ \\
Weibull & $M R=\exp (-t / k)^{n}$ \\
Diffusion approach & $M R=a \times \exp (-k t)+(1-a) \times \exp (-k b t)$ \\
Wang and Singh & $M R=1+a . t+b . t^{2}$ \\
\hline
\end{tabular}


The parameters of each equation were identified by using the non-linear optimization method of Marquardt-Levenberg (CurveExpert and Origin 6.1 sotware). To assess the goodness of the fit, the correlation coefficient (r) (Eq. 2) and standard error (EST) (Eq. 3) were calculated.

$$
\begin{gathered}
r=\sqrt{1-\frac{\sum_{i=1}^{n_{\text {exp.data }}}\left(M R_{\exp i}-M R_{\text {cali }}\right)^{2}}{\sum_{i=1}^{n_{\text {exp.data }}\left(M R_{\text {exp }}-M R_{\text {exp } i}\right)^{2}}}} \\
E S T=\sqrt{\frac{\sum_{i=1}^{n_{\text {exp data }}\left(M R_{\text {exp } i}-M R_{\text {cali }}\right)^{2}}}{n_{\text {exp.data }}-n_{\text {param }}}}
\end{gathered}
$$

Where MRcali is the calculated value of the non-dimesional moisture content by using the tested model, MRexpi is the experimental value of equilibrium moisture content, nparam is the number of parameters of the particular model and nexp.data is the number of experimental points. The mean value of the non-dimesional moisture content ( $\overline{M R})$ was calculated as follows:

$$
\overline{M R}=\frac{1}{n_{\text {exp.data }}} \sum_{i=1}^{n_{\text {exp.data }}} M R_{\exp i}
$$

\section{Results and discussion}

\subsection{Experimental drying kinetics}

The initial moisture content of henna leaves was $2.33 \mathrm{~kg}$ water $/ \mathrm{kg}$ d.m. Temperature affects the experimental drying kinetics; the higher the temperature the faster the process (Fig. 3). Thus, the time needed to achieve a moisture content of $1 \mathrm{~kg}$ water $/ \mathrm{kg} \mathrm{d} . \mathrm{m}$. was $2.64 \mathrm{~h}$ at 40 ${ }^{\circ} \mathrm{C}, 1.94 \mathrm{~h}$ at $50{ }^{\circ} \mathrm{C}$ and $1.25 \mathrm{~h}$ at $60^{\circ} \mathrm{C}$.

Ultrasound application significantly accelareted drying of Henna leaves (Fig. 4). In this sense, at $40{ }^{\circ} \mathrm{C}$, drying time in experiments carried out with ultrasound was $50 \%$ lower than the needed in experiments carried out without ultrasound application. The influence of ultrasound in drying rate was quite similar at the different temperatures tested. 


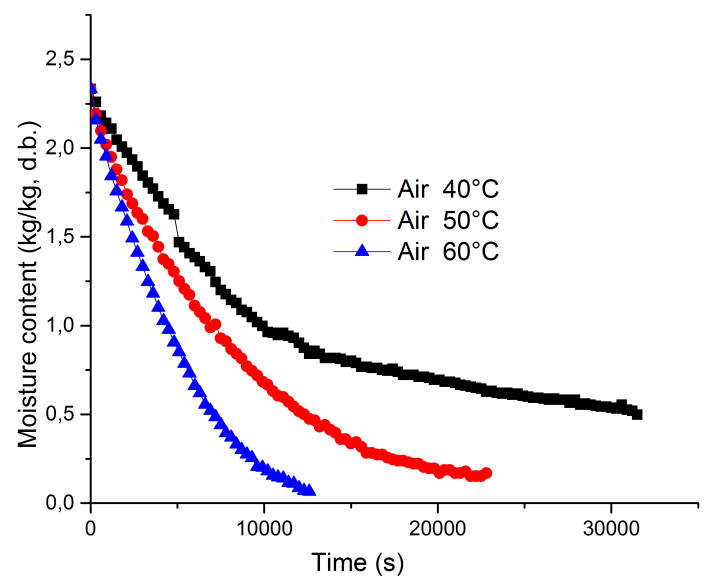

Fig. 3 Experimental drying kinetics of the Henna leaves without ultrasound application .

\subsection{Modelling}

Among the different models tested, the Weibull model gave the best fit, that is, the highest value of $r$ parameter and the lowes of EST. The model parameters identified are shown in Table 2. The studied process variables, temperature and ultrasound application, did not significantly affect $(\mathrm{p}<0.05)$ the $n$ parameter. This parameter is related with the product considered.

On the contrary, $k$ parameter, which is inversely proportional to the drying rate, was affected by both, temperatue and ultrasound application. Thus, the higher the temperature, the lower the $k$ value, which indicates a faster drying.

The application of ultrasound also reduced the identified $\mathrm{k}$ figures, meaning a lower time of drying becoming this influence more important at moderate drying temperature. Thus, at ${ }^{\circ} \mathrm{C}$, the $k$ identified in Air+us experiments was $27 \%$ lower than the idientified in Air experiments. This difference was $16 \%$ at $50{ }^{\circ} \mathrm{C}$ and only $7 \%$ at $60{ }^{\circ} \mathrm{C}$. 
Table 2. Weibull model parameters identified by fitting to the experimental drying kinetics of henna leaves at different temperature and without (Air) and with (Air+us) ultrasound application. Correlation coefficient (r)and standar error (EST)

\begin{tabular}{cccccc}
\hline Type of experiment & Temperature $\left({ }^{\circ} \mathbf{C}\right)$ & $\mathbf{n}$ & $\mathbf{K}$ & $\mathbf{r}$ & $\mathbf{E S T}$ \\
\hline Air & 40 & 0.900 & 14434.7 & 0.9948 & 0.0208 \\
Air+us & 40 & 1.062 & 10523.7 & 0.9985 & 0.0136 \\
Air & 50 & 1.088 & 7495.6 & 0.9979 & 0.0173 \\
Air+us & 50 & 0.993 & 6286.0 & 0.9962 & 0.0207 \\
Air & 60 & 1.114 & 4705.3 & 0.9939 & 0.0271 \\
Air+us & 60 & 1.171 & 4391.8 & 0.9900 & 0.0322 \\
\hline
\end{tabular}

Henna leaves dried at $40{ }^{\circ} \mathrm{C}$, with or without ultrasound application, kept their green color while samples dried at higher temperature showed a brown color. This fact indicates the limited deterioration of the active product at the lowest temperature tested compared with the highest ones. Therefore, ultrasound application represent an alternative to intensify drying rate during drying at milder tempertures and preserving product quality.

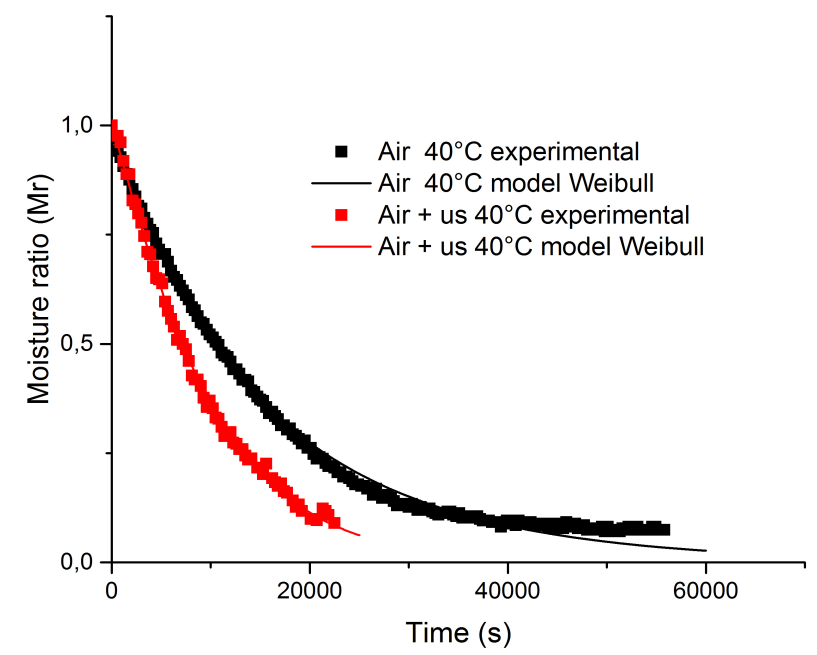

Fig. 4 The experimental moisture ratio described by the Weibull model of the Henna leaves without and with ultrasound. 


\section{Conclusions}

The drying kinetics of henna leaves was affected by both temperature and ultrasound application. The higher the temperature the faster the process. However, the green color of samples, which is a measurement of the quality of final product, was maintained only at the lowest temperature tested, $40^{\circ} \mathrm{C}$. The ultrasound application accelerate the drying. Its application at low temperature was an interesting alternative to accelerate the drying maintain the quality.

\section{Acknowledgements}

The authors acknowledge the financial support of INIA-ERDF throughout the project RTA2015-00060-C04-02

\section{References}

[1] Fortin, D.L.O.M. ; Maynart, G. Plantes médicinales du Sahel; Enda-Editions : Dakar, 2000 .

[2] Tiris, C.; Tiris, M.; Dincer, I. Energy efficiency of a solar drying system. International Journal of Energy Research 1996, 20, ,767-770,

[3] AOAC . Official method of analysis of the Association of Official Analytical Chemists International. 16th edition, 3rd revision, March, 1997.

[4] Carcel, J.A.; García-Perez, J.V.; Riera, E.; Mulet, A. Influence of high intensity ultrasound on drying kinetics of persimmon. Drying Technology 2007, 25, 185-193.

[5] Riera, E.; García-Perez, J.V.; Carcel, J.A.; Acosta, V.; Gallego-Juarez, J.A. Computational study of ultrasound-assisted drying of food materials. In Innovative Food Processing Technologies: Advances in Multiphysics Simulation. Knoerzer, K., Juliano, P., Roupas, P., Versteeg, C. Eds.; John Wiley \& Sons Ltd, 2011, 265-301.

[6] Do Nascimento, E.M.G.C; Mulet, A.; Ramírez-Ascherí, J.L.; Piler De Carvalho, C.W.; Cárcel, J.A.. Effects of high-intensity ultrasound on drying kinetics and antioxidant properties of passion fruit peel. Journal of Food Engineering 2016, 170, 108-118.

[7] Lahsasni, S.; Kouhila, M.; Mahrouz, M.; Idlimam, A.; Jamali, A. Thin layer convective solar drying and mathematical modeling of prickly pear peel (Opuntia ficus indica). Energy 2004, 29(2), 211-224.

[8] Belghit, A.; Kouhila, M.; Boutaleb, B.C. Experimental Study of Drying Kinetics by Forced Convection of Aromatic Plants. Energy Conversion and Management 2000, 41(12), 1303-1321.

[9] Santacatalina, J.V.; Rodríguez, O.; Simal, S.; Cárcel, J.A.; Mulet, A.; García-Pérez, J.V. Ultrasonically enhanced low-temperature drying of apple: Influence on drying kinetics and antioxidant potential. Journal of Food Engineering 2014, 138, 35-44. 